\title{
Health Awareness among University Students in Jordan
}

\author{
Mamdouh M. Ashraah ${ }^{1}$, Ahmad M. Mahasneh ${ }^{2}$, Aeshah A. Al-Sawalmeh ${ }^{2}$ \& Atieh I. Abusheikh ${ }^{3}$ \\ ${ }^{1}$ Department of Curricula, Faculty of Educational Science, Hashemite University, Zaeqa, Jordan \\ ${ }^{2}$ Department of Educational Psychology, Faculty of Educational Science, Hashemite University, Zarqa, Jordan \\ ${ }^{3}$ Faculty of Princess Rahma, Al-Balqa Applied University, Jordan \\ Correspondence: Ahmad M. Mahasneh, Department of Educational Psychology, Faculty of Educational Science, \\ Hashemite University, Zarqa 133024, Jordan. Tel: 962-799-780-290. E-mail: \\ dahmadmahasneh1975@yahoo.com
}

Received: July 27, 2013 Accepted: September 12, 2013 Online Published: November 20, 2013

doi:10.5539/res.v5n5p197 URL: http://dx.doi.org/10.5539/res.v5n5p197

\begin{abstract}
The primary purpose of this study was to determine the level of health awareness among university students in Jordan. The sample of the study consisted of (860) male and female students from different colleges at the Hashemite University during the second semester of the academic year 2012/2013, who were exposed to the health awareness scale. To analyze the gathered data, means, standard deviations, t-test and one-way ANOVA were calculated. Additionally, results indicated that the degree of health awareness for the Hashemite University students was low, and that there were statistically significant differences for the level of health awareness for the Hashemite University students ascribed to the variables of gender, specialization, and academic level and GPA.
\end{abstract}

Keywords: health awareness, university students

\section{Introduction}

The recent decades have witnessed a radical change in the diseases' types and their outbreak in community, from infecting diseases to chronic ones, particularly the diseases which are called the living style illnesses such as heart diseases, blood pressure diseases, and diabetes as well as the increase in other related problems like drug addiction, and misuse of medications. Besides, there are the other negative effects of excessive growth in population, environmental pollution, malnutrition and related illnesses which all lead to failure to individuals' mental and physical capacity (Al-Amoudi, 2007).

Health awareness includes various aspects that involve all the healthy behavioral and cognitive needs. Some of these aspects include the personal health and the way humans protect their health, the environmental health and the important pollutants, the psychological health that is related to the self healthiness, smoking and drugs and their harmful effects, in addition to infecting and disinfecting diseases and their ways of transition.

Abdo (2003) defines health awareness as educating individuals and increasing their knowledge so as to change their behavior and habits especially in the case of diseases' spread in community, as well as instilling habits and traditions that could enforce the health aspect such as sport practicing and nutrition. Ahmad (2012) sees that the health-mindful person is the ideal individual who enjoys high levels of health represented by healthy, social, mental, and physical integration. She also sees that practicing sportive activities helps in avoiding heart diseases, blood pressure diseases, diabetes, and obesity considering that the health aspect includes 2 main fields: health education represented by acquiring knowledge and information related to health as well as health awareness which is represented by the practical application of that knowledge and information. O'liewa (1999) defines health awareness as a translation of health knowledge and experiences into behavioral patterns among individuals.

On the other hand, Salameh mentioned in Al-Ahmadi (2003) identifies it as the individuals' acquaintance of health knowledge and facts, and their sense of responsibility towards their own and others' health. It is also the deliberately health practice that results from understanding and persuasion, and the transfer of these health practices into unconscious habits. Mursi (2005) identifies health awareness as the introduction of health facts, data and information that are related to health and disease for the community individuals in an attempt to reach the case when every individual is ready to respond to health instructions and guidelines. 
After reviewing the different definitions of health awareness, researchers see that health awareness implies delivering the health information to people correctly and comprehensibly so as to influence their daily life and behavior. Enhancing the students' level of health awareness is an educational issue since the decrease in the students' health awareness level is fundamental in the educational domain, and is caused by lack of knowledge among students about how to deal with health problems properly. Thus, the unhealthy behavior is ascribed to the students' unfamiliarity with health habits and attitudes that could enable them avoid diseases (Al-Farra, 1984).

Abd Al-Haqq \& Others (2012) conducted a study that aimed at identifying the health awareness level for Al-Najah National University and Jerusalem University, as well as pointing out the differences in the health awareness level according to the variables of university, college and marks' average. The findings of the study revealed that the level of health awareness among the sample participants was medium. Results also indicated that there are differences in the level of students' health awareness according to the variable of university for the benefit of Jerusalem University students and the variable of college for the benefit of scientific colleges, and the variable of marks' average for the benefit of the highest average.

Al-Qadoumi (2005) found out the level of health awareness and the sources for getting health information for the Arabian volleyball clubs' players as well as identifying the level of health awareness in accordance to the variables of playing experience and the players' academic level. The results showed that the participants' health awareness level was high, and there were not significant differences according to the variables of playing experience, the players' academic level and the interaction between them. Besides, the study found out that media was the ultimate resource for getting health-related information about the players. Al-Ahmadi's (2003) study aimed at identifying the level of secondary stage students' health awareness and their health attitudes at Madinah, and the results asserted that the students' health awareness level was low. Moreover, Al-Ali (2001) conducted a study that aimed at identifying the health culture level among the public schools' upper basic stage students in Jenin, as well as defining the impact of the variables of gender, place of living, mother's academic level, father's academic level and students' achievement in science upon the level of health culture. The findings revealed that the participants' health culture level was good, and that there are statistically significant differences in the level of health culture according to the variables of gender, place of living, mother's academic level, father's academic level and students' achievement in science.

The study of Khataibeh \& Rawashdeh (2003), which had the aim of identifying the level of health awareness among the Jordanian colleges' female students, indicated that the level of health awareness was decreasing since it was less that the accepted level. The findings of the study were for the benefit of $2^{\text {nd }}$-year level as compared to $1^{\text {st }}$-year, and for the benefit of professional specialty as compared to academic one and for the benefit of academic specialty as compared to commercial one.

\section{Statement of the Problem}

The interest in students' health aspect is considered one of the basic goals of education which is accomplished through helping students acquire health knowledge, developing proper attitudes, and taking proper health decisions that protect life and individuals from diseases. The problem of this study is represented in identifying the health awareness level for the Hashemite University students in light of some variables. More specifically, this study attempts to answer the following questions:

R.Q.1: What is the level of health awareness among Hashemite University students?

R.Q.2: Are there statistically significant differences in the level of Hashemite University students' health awareness ascribed to the variables of (gender, specialization, academic level and GPA)?

\section{Importance of the Study}

This study is important for the following reasons: (1) It addresses one of the generation's important issues that tackle the most important aspect since the case of health is a global issue that all communities suffer from. (2) The findings of this study help curriculum experts when planning programs so as to include health principles.(3) It paves the way for researchers to conduct other studies on other samples rather than the one involved in this study.

\section{Methodology}

\subsection{Participants}

The study population consisted (15230) of the Hashemite University students enrolled in the summer semester for BA degree in the academic year 2012/2013, distributed over the different University Faculties. The study sample consisted of (860) male and female students (5\% of the study population) representative of the various 
faculties and academic levels. Four sections were selected out of the University Elective Courses the University provides for all the BA grade students.

\subsection{Instrument}

The researchers developed a tool for measuring the level of students' awareness after reviewing the theoretical literature and other related studies as well as benefiting from the scale designed by (Abd Al-Haqq \& Others, 2012). The tool of the study consisted of (29) items distributed on the following domains: the nutrition aspect having 8 items, the personal health aspect with 5 items, sportive activities having 8 items and finally 8 items were allocated for the body domain. The answer scale included the type of Lickert's fivefold scale where 5 points were allocated for the answer (strongly agree), 4 points for (agree), 3 points for (neutral), 2 points for (disagree), and 1 point for the answer (strongly disagree). To ensure the validity of the tool, it was judged by a group of experts in analogy and assessment, physical education and medical sciences. Their notes were considered as for modifying the items' formulation as well as deleting the unsuitable ones.

The scale's stability was ensured using the formula of Cronbach Alpha for interior consistency which was $(0.81)$ for the nutrition domain, (0.87) for the personal health domain, $(0.84)$ for the sportive activities domain and (0.82) for the body aspect.

\subsection{Data Collection}

After acquiring the instructor permission, the questionnaire administrated was during regular class periods to student in the second semester of the 2012-2013 academic years. The students received written instruction that specified the purpose of the study and explained the procedure followed while responding to the questions. In particular, the students were told that there were no rights or wrong response. Students asked to return the questionnaires to the class instructor who passed them it on to the researcher.

\subsection{Data Analysis}

The data collected from all participants were coded, entered onto the SPSS spreadsheets, and analyses using software package SPSS version 17. Descriptive statistics for all variables in this study were examined using SPSS frequencies. The minimum and maximum values of each item were examined for accuracy of data entry by inspecting any out-of-range values. No out-of-range values were found. Missing subjects were not detected either. The results of the study are addressed by each objective.

\section{Results}

Following is the demonstration of the most important findings according to the questions of the study:

\subsection{Results Related to the First Question: What Is the Level of Health Awareness among the Students of the} Hashemite University?

To answer this question, means and standard deviations for the participants' responses were calculated as shown in Table 1.

Table 1. Means \& SDs for the participants' answers for the study's tool

\begin{tabular}{llccc}
\hline No. & Item & mean & SD & $\begin{array}{c}\text { Awareness } \\
\text { degree }\end{array}$ \\
& & & & \\
\hline 1 & I am interested in having daily perfect and complete food. & 2.84 & 1.31 & Low \\
2 & I can't have my breakfast due to time limits. & 2.60 & 1.34 & Low \\
3 & I have too many cold and hot drinks between basic meals. & 2.12 & 1.02 & Low \\
4 & Drinking tea \& coffee helps me concentrate. & 2.74 & 1.37 & Low \\
5 & I am interested in recognizing the food items that provides energy. & 2.79 & 1.33 & Low \\
6 & I try to be fit with a proper weight. & 2.48 & 1.18 & Low \\
7 & I eat too much fresh fruit and vegetables. & 2.50 & 1.18 & Low \\
8 & I try to avoid fried food and prefer the cooked. & 3.18 & 1.32 & medium \\
Total & 2.66 & 1.26 & Low \\
& $\quad$ The personal health domain & & & \\
1 & I am interested in adequate sleeping and relaxing time. & 2.16 & 1.32 & Low \\
\hline
\end{tabular}


2 I am interested in having a bath esp. after practicing exercises.

3 I choose proper clothes that suit the atmosphere temperature.

$4 \quad$ I like to live in a healthy, sunny \& well-ventilated house.

5 I concern about clipping my fingers \& toes' nails when needed

\section{Total}

\section{The sportive practice domain}

1 I walk for long distances to activate the blood circulation .

2 I like to take part in sportive \& entertaining activities.

3 I worry about allocating time for some exercises.

$4 \quad$ I give up practicing activities that cause accidents.

5 I avoid practicing exercises when feeling tired.

6 I participate in sports so as to feel happy and satisfied.

7 I am concerned with conducting a medical investigation before joining the team.

8 I am concerned with conducting a medical investigation after being healed from accident.

Total

\section{The body domain}

1 I worry about the healthy conditions for proper sitting during study.

2 I worry about the proper walking conditions.

3 I don't exaggerate in my ability of lifting things.

$4 \quad$ I am concerned with knowing how to pick up things.

5 I am concerned with knowing how to protect my body.

6 I am interested in knowing the processes of my body's biology .

$7 \quad$ I avoid exhaustion and physical stress.

8 Sporting exercises helps my body to perform well.

Total

The Entire health awareness degree

$\begin{array}{lll}1.54 & 0.77 & \text { Low } \\ 1.70 & 1.04 & \text { Low } \\ 1.50 & 0.84 & \text { Low } \\ 1.65 & 0.96 & \text { Low } \\ 1.71 & 0.99 & \text { Low }\end{array}$

$\begin{array}{lll}2.58 & 1.16 \quad \text { Low }\end{array}$

$2.76 \quad 1.35 \quad$ Low

$\begin{array}{lll}2.88 & 1.19 \quad \text { Low }\end{array}$

$2.88 \quad 1.27 \quad$ Low

$2.63 \quad 1.18 \quad$ Low

$2.48 \quad 1.23 \quad$ Low

$3.13 \quad 1.34 \quad$ medium

$2.96 \quad 1.36 \quad$ Low

$2.79 \quad 1.26 \quad$ Low

$\begin{array}{lll}2.39 & 1.27 \quad \text { Low }\end{array}$

$2.38 \quad 1.18 \quad$ Low

$2.41 \quad 1.11 \quad$ Low

$2.29 \quad 1.06 \quad$ Low

$\begin{array}{lll}1.98 & 1.05 \quad \text { Low }\end{array}$

$2.46 \quad 1.09 \quad$ Low

$2.24 \quad 1.11 \quad$ Low

$\begin{array}{lll}1.89 & 1.03 \quad \text { Low }\end{array}$

$2.26 \quad 1.11 \quad$ Low

$2.36 \quad 1.16 \quad$ Low

Table 1 shows that the entire degree for the Hashemite University students' health awareness level was low with an average of (2.36). The domain of sportive activities practice occupied the first rank for an average of (2.79), followed by the domain of nutrition that had an average of (2.66). Then comes the domain of body for an average of (2.66), and lastly comes the personal health aspect which had an average of (1.71).

5.2 Results Related to the Second Question: Are There Statistically Significant Differences in the Level of Hashemite University Students' Health Awareness Ascribed to the Variables of (Gender, Academic Major, Studying Level and Marks' Average)?

To answer this question, means, standard deviations and t-test were calculated in accordance to the variable of gender as displayed in Table 2 .

Table 2. Means \& SDs according to gender

\begin{tabular}{|c|c|c|c|c|c|c|}
\hline \multirow[t]{2}{*}{ Domain } & \multicolumn{2}{|c|}{ Males } & \multicolumn{2}{|c|}{ Females } & \multirow[t]{2}{*}{ t-value } & \multirow[t]{2}{*}{ significance } \\
\hline & mean & SD & mean & SD & & \\
\hline Nutrition & 2.46 & 0.62 & 2.77 & 0.54 & -7.542 & 0.000 \\
\hline Personal health & 1.78 & 0.69 & 1.67 & 0.62 & 2.341 & 0.019 \\
\hline Sportive activities & 2.63 & 0.75 & 2.88 & 0.75 & -4.833 & 0.000 \\
\hline body & 2.32 & 0.63 & 2.22 & 0.68 & 2.210 & 0.000 \\
\hline
\end{tabular}


As seen in Table 2, there are statistically significant differences in the level of Hashemite University students' health awareness within the aspects of nutrition, personal health, sportive activities practice and body ascribed to gender. Moreover, means, SDs and t-test were calculated for the variable of specialization as seen in table (3).

Table 3. Means \& SD according to specialization

\begin{tabular}{ccccccc}
\hline \multirow{2}{*}{ Domain } & \multicolumn{2}{c}{ scientific } & \multicolumn{2}{c}{ literary } & t-value & \multirow{2}{*}{ significance } \\
\cline { 2 - 5 } & mean & SD & mean & SD & & \\
\hline Nutrition & 2.61 & 0.60 & 2.81 & 0.53 & -4.470 & 0.000 \\
Personal health & 1.69 & 0.64 & 1.76 & 0.67 & -1.397 & 0.163 \\
Sportive activities & 2.78 & 0.71 & 2.80 & 0.87 & 0.250 & 0.803 \\
body & 2.28 & 0.61 & 2.18 & 0.79 & 2.008 & 0.045 \\
\hline
\end{tabular}

$\mathrm{P}<0.05$

As seen in Table 3, there are statistically significant differences in the level of Hashemite University students' health awareness within the aspects of nutrition, and body ascribed to specialization, whereas there were no statistically significant differences ascribed to the variable of specialization within the domains of sportive practice and personal health.

One-way ANOVA was used to identify the significance of these differences according to the variable of academic level as noted in Table 4.

Table 4. Results of one-way ANOVA in accordance to academic level

\begin{tabular}{|c|c|c|c|c|c|c|}
\hline domain & $\begin{array}{l}\text { Source of } \\
\text { variance }\end{array}$ & $\begin{array}{l}\text { Sum of } \\
\text { squares }\end{array}$ & $\begin{array}{l}\text { Degrees of } \\
\text { freedom }\end{array}$ & $\begin{array}{c}\text { Mean of } \\
\text { squares }\end{array}$ & f-value & $\begin{array}{c}\text { Significance } \\
\text { level }\end{array}$ \\
\hline \multirow[t]{3}{*}{ nutrition } & $\begin{array}{l}\text { Between } \\
\text { groups }\end{array}$ & 11.540 & 3 & 3.847 & 11.258 & 0.000 \\
\hline & Inside groups & 292.481 & 856 & 0.342 & & \\
\hline & total & 304.021 & 859 & & & \\
\hline \multirow[t]{3}{*}{ Personal health } & $\begin{array}{l}\text { Between } \\
\text { groups }\end{array}$ & 22.645 & 3 & 7.548 & 18.949 & 0.000 \\
\hline & Inside groups & 340.988 & 856 & 0.398 & & \\
\hline & total & 363.633 & 859 & & & \\
\hline \multirow[t]{3}{*}{$\begin{array}{l}\text { Practicing } \\
\text { exercises }\end{array}$} & $\begin{array}{l}\text { Between } \\
\text { groups }\end{array}$ & 28.708 & 3 & 9.569 & 17.488 & 0.000 \\
\hline & Inside groups & 468.407 & 856 & 0.547 & & \\
\hline & total & 497.115 & 859 & & & \\
\hline \multirow[t]{3}{*}{ body } & $\begin{array}{l}\text { Between } \\
\text { groups }\end{array}$ & 10.369 & 3 & 3.456 & 7.969 & 0.000 \\
\hline & Inside groups & 371.261 & 856 & 0.434 & & \\
\hline & total & 381.630 & 859 & & & \\
\hline
\end{tabular}

$\mathrm{P}<0.05$

Table 4 indicates the existence of statistically significant differences in the level of health awareness for the Hashemite University students within the aspects of nutrition, personal health, body and sportive activities ascribed to the variable of academic level. F-value for the nutrition domain reached (11.258), whereas the personal health aspect has a value of (18.949). The f-value for the sportive practice was (17.488), and for the body aspect was (7.969). In order to determine the significance of these differences between these means, LSD test for post comparisons was utilized as shown in table (5). 
Table 5. Results of LSD test for post comparisons according to academic level

\begin{tabular}{ccccc}
\hline Study level & $1^{\text {st }}$ year & $2^{\text {nd }}$ year & $3^{\text {rd }}$ year & $4^{\text {th }}$ year \\
\hline $1^{\text {st }}$ year & $*$ & & \\
$2^{\text {nd }}$ year & $*$ & $*$ & \\
$3^{\text {rd }}$ year & & $*$ & \\
$4^{\text {th }}$ year & & & \\
\hline 0.05 & & &
\end{tabular}

Table 5 indicates that there are statistically significant differences in the students' health awareness level ascribed to the variable of studying level for the benefit of $1^{\text {st }}, 3^{\text {rd }}$ and $4^{\text {th }}$ year students as compared to the $2^{\text {nd }}$ year students.

One-way ANOVA was used to determine the significance of these differences according to the variable of GPA, as illustrated in Table 6.

Table 6. Results of one-way ANOVA in accordance to GPA

\begin{tabular}{|c|c|c|c|c|c|c|}
\hline domain & $\begin{array}{l}\text { Source of } \\
\text { variance }\end{array}$ & $\begin{array}{l}\text { Sum of } \\
\text { squares }\end{array}$ & $\begin{array}{l}\text { Degrees of } \\
\text { freedom }\end{array}$ & $\begin{array}{l}\text { Mean of } \\
\text { squares }\end{array}$ & f-value & $\begin{array}{c}\text { Significance } \\
\text { level }\end{array}$ \\
\hline \multirow[t]{4}{*}{ nutrition } & $\begin{array}{c}\text { Between } \\
\text { groups }\end{array}$ & 11.028 & 3 & 3.676 & 10.740 & 0.000 \\
\hline & Inside groups & 292.992 & 856 & & & \\
\hline & total & 304.021 & 859 & & & \\
\hline & & & & 0.342 & & \\
\hline \multirow[t]{4}{*}{ Personal health } & $\begin{array}{c}\text { Between } \\
\text { groups }\end{array}$ & 2.907 & 3 & 0.969 & 2.300 & 0.000 \\
\hline & Inside groups & 360.725 & 856 & & & \\
\hline & total & 363.633 & 859 & & & \\
\hline & & & & 0.421 & & \\
\hline \multirow[t]{3}{*}{$\begin{array}{l}\text { Practicing } \\
\text { exercises }\end{array}$} & $\begin{array}{l}\text { Between } \\
\text { groups }\end{array}$ & 32.347 & 3 & 10.782 & 19.858 & 0.000 \\
\hline & Inside groups & 464.768 & 856 & 0.543 & & \\
\hline & total & 497.115 & 859 & & & \\
\hline \multirow[t]{3}{*}{ body } & $\begin{array}{l}\text { Between } \\
\text { groups }\end{array}$ & 31.587 & 3 & 10.529 & 25.748 & 0.000 \\
\hline & Inside groups & 350.043 & 856 & 0.409 & & \\
\hline & total & 381.630 & 859 & & & \\
\hline
\end{tabular}

$\mathrm{P}<0.05$

Table 6 indicates the existence of statistically significant differences in the level of health awareness for the Hashemite University students within the aspects of nutrition, personal health, body and sportive activities ascribed to the variable of GPA. F-value for the nutrition domain reached (10.740), whereas the personal health aspect has a value of (2.300). The f-value for the sportive practice was (19.858), and for the body aspect was (25.748).

In order to determine the significance of these differences between these means, LSD test for post comparisons was utilized as shown in Table 7.

Table 7. Results of LSD test for post comparisons according to GPA

\begin{tabular}{ccccc}
\hline Marks' average & Excellent & Very Good & Good & Acceptable \\
\hline Excellent & & & & \\
Very Good & & $*$ & $*$ & \\
Good & $*$ & $*$ & \\
Acceptable & $*$ & & \\
$\mathrm{P}<0.05$ & & &
\end{tabular}


Table 7 indicates that there are statistically significant differences in the students' health awareness level ascribed to the variable of average for the benefit of students whose average is very good and above.

\section{Discussion}

This study aimed at identifying the level of health awareness for the Hashemite University students according to some variables, and the study sample contained (860) male and female students from different colleges during the $2^{\text {nd }}$ semester of the year 2012/2013 who were exposed to the health awareness scale.

The researchers developed a tool for measuring the university students' awareness level, and this tool consisted of (29) items distributed among the domains of (nutrition, personal health, practice of sports, and body).

The results indicated that the entire degree for the students' health awareness level was low registering a mean of (2.36). The first rank was taken by the domain of sport practice with an average of (2.79), followed by the domain of nutrition with an average of (2.66). Then comes the domain of body with an average of (2.26), and lastly the domain of personal health with an average of (1.71). This result can be explained that the interest in health awareness, whether on the level of general or higher education, was not adequate, which consequently affected the degree of health awareness for the Hashemite University students that were low.

The findings of this study are compatible with the results of the studies of Al-Ahmadi (2003), and Khataibeh \& Rawashdeh (2003) which revealed that the students' health awareness level was low. Moreover, this study revealed the existence of significant differences in the level of health awareness for the Hashemite University students within the aspects of nutrition, personal health, body and sport activities ascribed to the variable of gender.

This result can be justified that females are more caring for their external appearance than males. Also, this study showed that there were significant differences in the level of health awareness within the nutrition and body aspects ascribed to the variable of academic specialty, whereas there were no significant differences in the level of health awareness ascribed to the variable of academic specialty within the domain of practicing exercises and personal health. This result can be justified through the nature of courses scientific colleges' students have compared to the students of literary colleges.

In addition, the study indicated the existence of significant differences in the university students' health awareness level ascribed to the variable of academic level for the benefit of $1^{\text {st }}, 3^{\text {rd }}$ and $4^{\text {th }}$ year students compared to the $2^{\text {nd }}$ year students. Moreover, there were significant differences in the level of health awareness for the university students ascribed to the variable of GPA for the benefit of students who got very good and above. These results can be explained that students who got high averages are more acquainted with health issues compared to other students who got low marks. The results of this study are compatible with the results of the following studies: Susan's et al (2001), Al-Qadoumi's (2005), and Abd Al-Haqq \& Others' (2012).

In light of these results, the researchers recommend the following: (1) Conducting a similar study on other samples of teaching stages. (2) Including health concepts within the teaching curricula. (3) Conducting a study that aims at assessing the efficacy of some programs in raising the students' awareness level.

\section{References}

Abd Al-Haqq, E., Shana'eh, M., Nu'erat, Q., \& Al-Amad, S. (2012). The Health Awareness Level for the Students of Al-Najah National University \& Jerusalem University. The Journal of Al-Najah University for Researches (Humanitarian Sciences), 26(4), 939-958.

Abdo, Y. (2003). A Suggested Program for Developing Health Concepts among the $6^{\text {th }}$ Grade Students of Ghaza. Unpublished MA dissertation, The Islamic University, Ghaza.

Ahmad, N. (2012). The Effectiveness of Health Education Methods in Instilling \& Disseminating Health Information for Building the Sudanese Health Community of Practice. The National Centre for Researches, The Centre of Documentation \& Information (pp. 1762-1781).

Al-Ahmadi, A. (2003). The Level of Second Secondary Students' Health Awareness and its relation to their Health Attitudes in Medina. Unpublished MA dissertation, Um Al-Qura University.

Al-Ali, F. S. (2001). The Level of Health Education Among the Upper Basic Stage Students in the Public Schools of Jenin. Unpublished MA dissertation, Al-Najah National University, Nablus, Jerusalem.

Al-Amoudi, H. (2007). The Efficacy of a Suggested Health Education Program for Developing the Health among the Middle Stage Students in Makah. Unpublished $\mathrm{PhD}$ dissertation, The Islamic University, Ghaza. 
Al-Qadoumi, A. N. (2005). The Level of Health Awareness and The Resources of Health Information Among the Volleyball Arabian Clubs' Players. The Journal of Educational and Psychological Sciences (College of Education), Bahrain University, 6(1), 223-263.

Khataibeh, A., \& Rawashdeh, I. (2003). The Health Awareness Level of Jordanian Public Colleges' Female Students. The Journal of King Su'od University for Educational Sciences \& Islamic Studies, 15(1), 259-296.

Mursi, L. A. (2005). General Health \& Health Education. Al-Khreiji Dar for publishing \& distribution, Riyadh.

O'leiweh, A. A. (1999). Health in the Sporting Domain. Al-Ma'aref Association: Alexandria, Egypt.

Susan, B., Shiriki, K., Alfredo, M., \& Elizabeth, P. (2001). Acomparison of knowledge and attitudes about diet and health among 35 to 75 years - old adult in the United States and Geneva, Switzer land. American Journal of Public Healt ,91, 418-424. http://dx.doi.org/10.2105/AJPH.91.3.418

\section{Copyrights}

Copyright for this article is retained by the author(s), with first publication rights granted to the journal.

This is an open-access article distributed under the terms and conditions of the Creative Commons Attribution license (http://creativecommons.org/licenses/by/3.0/). 